\title{
مقاله يزووهشى
}

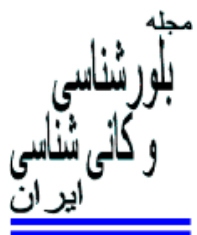

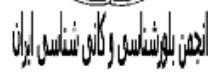

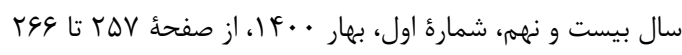

\section{بررسى اثر يايدارسازهاى آمينوالكلى بر ساختار بلورى، تاف نوارى و درخشندكى آبى

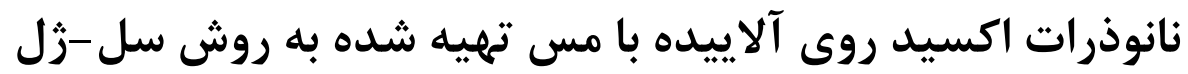

\author{
ابوالفضل بروان، جمال مظلوم*، فرهاد اسمعيلى قدسى، مر تضى صفرى \\ كروه فيزيك، دانشكده علوم بايه، دانشكاه كيلان، رشت، /يران
}

(دريافت مقاله: 99///19، نسخه نهايى: 99/D/TV )

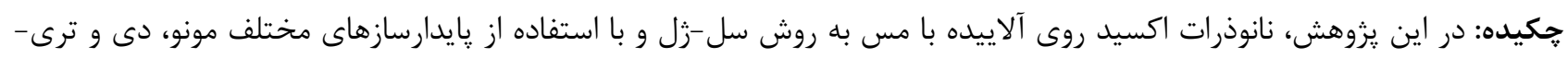

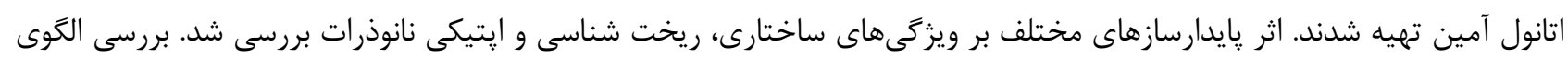

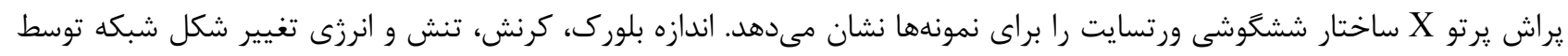

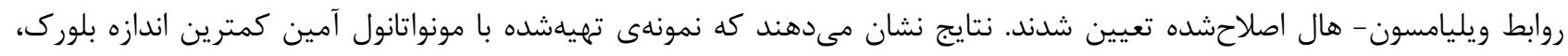

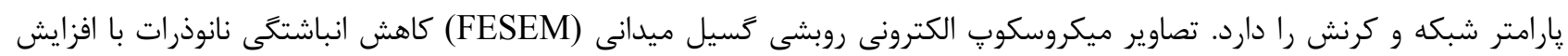

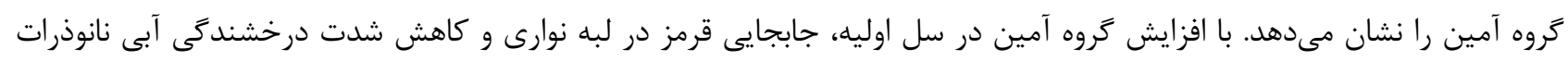

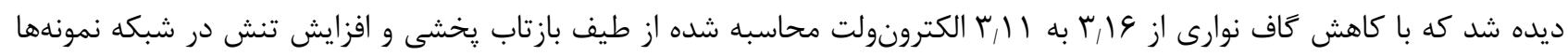
همخوانى دارد.

\section{وازههاى كليدى:اكسيد روى آلاييده با مس؛ نانوذرات، سل -زل؛ بإيدارساز؛ بارامترهاى ساختارى؛ كاف نوارى؛ نورتابى.}

آلاييده با مس با روشهاى متفاوتى تون فرآيند سل-زل

مقدمه

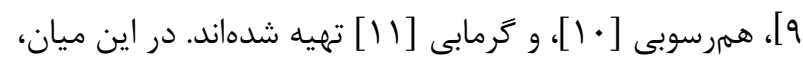

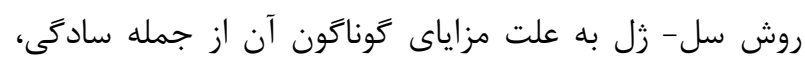

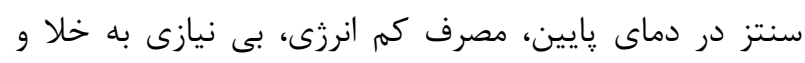

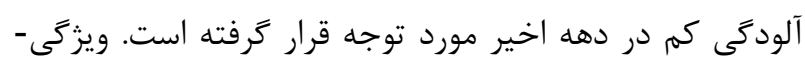

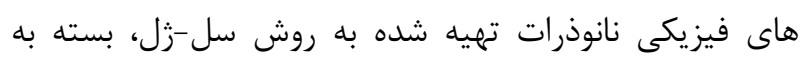

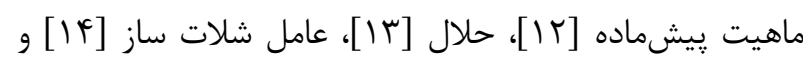

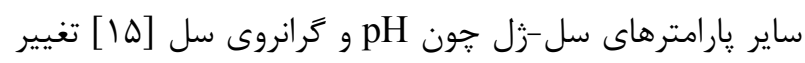

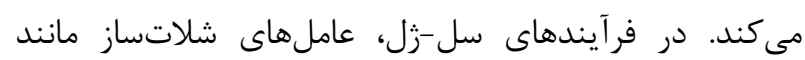

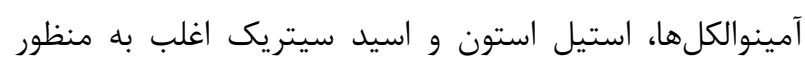

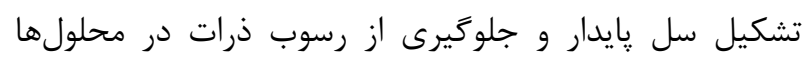

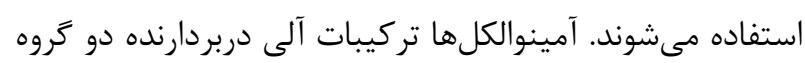

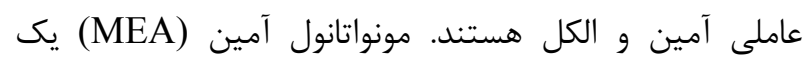

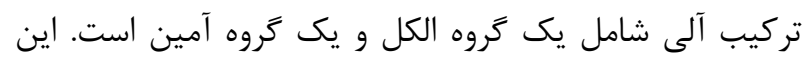

اكسيد روى (ZnO) يك نيمرساناى نوع n با كاف نوارى

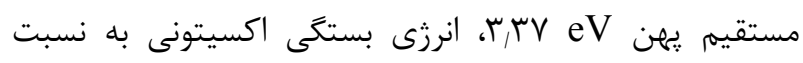

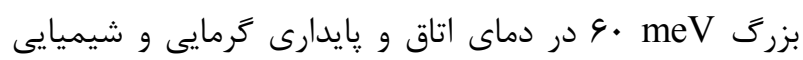

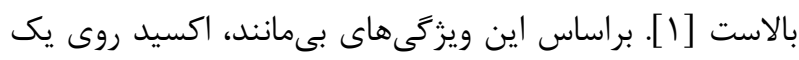

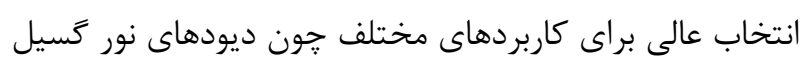

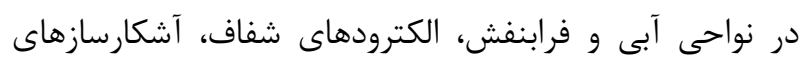

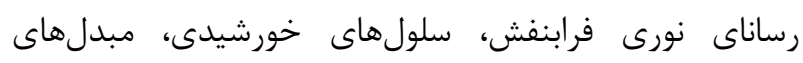

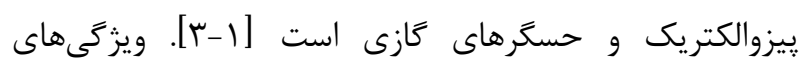
فيزيكى اكسيد روى با آلايش برخى فلزات واسط به طور قابل

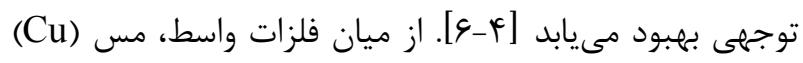

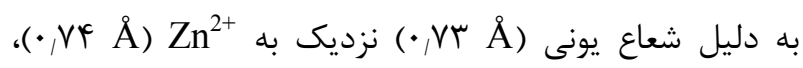

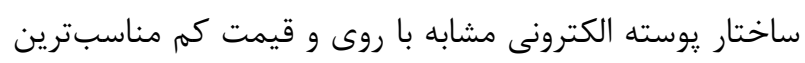

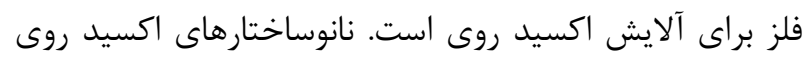


طيفسنجى تبديل فوريه فروسرخ (FTIR)، طيفسنجى بازتاب يخشى (DRS) و آزمايش نورتابى (PL) بررسى شد. روش تهيه نانوذرات اكسيد روى آلاييده با مس براى تهيه سل اكسيد روى آلاييده با مس، از استات روى دوآبه،

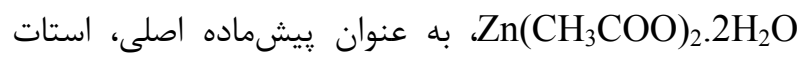
مس تكآبه، خالص به عنوان حلال، همجنين از سه بايدارساز متفاوت مونواتانول آمين (MEA)، دى عاتانول آمين (DEA) و (DEA) و ترى اتانول

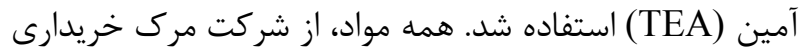

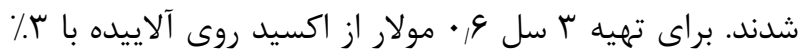

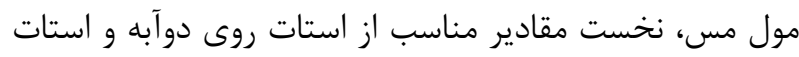

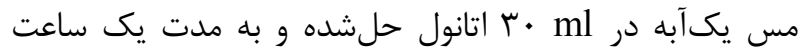

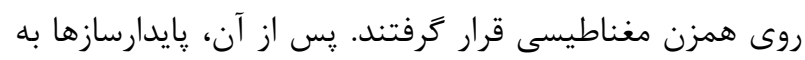
طور جداكانه به محلول اضافهشده و يك ساعت ديكر در دماى اتاق همزده شدند تا سرانجام، ؟ سل شفاف و همكن به رنغ

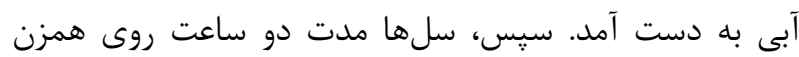
مغناطيسى در دماى V.

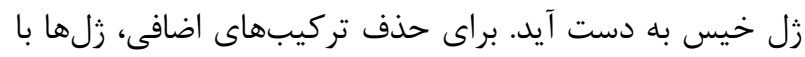

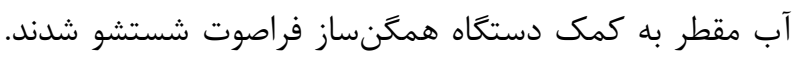

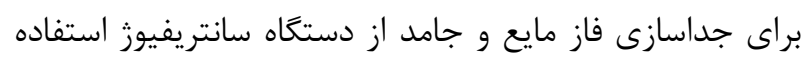
شد. اين فرايند شش بار انجام شد. سيس نمونهها در دماى Ir C C براى دو ساعت خشكسازى شدند. در پايان، نمونهها به مدت يك ساعت درون كوره Co C م كلسينه شدند.
ماده از واكنش اكسيد اتيلن با آمونياك مايع توليد مىشود.

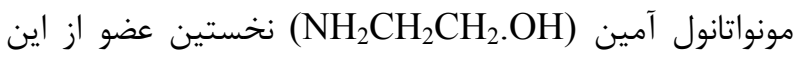
خانواده است. با جايكز ينى يك اتم هيدرورن در مونواتانول آمين آناين با تروه تشكيل مىشود، اگر همه اتمهاى هيدروزن در $\left(\mathrm{C}_{4} \mathrm{H}_{11} \mathrm{NO}_{2}\right)$ مونواتانول آمين با گروه اتانول آمين آمينوالكلهاى استفاده شده در شكل آ آورده شده است. ليكاند

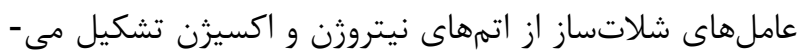
شود. به طور كلى، قدرت همارايى اتم اكسيرن نسبت به اتم نيتروزن بيشتر است. عوامل اصلى استفاده از آمينوالكلها حل-

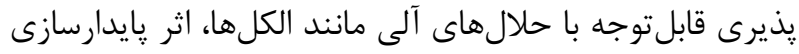

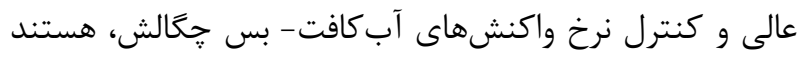

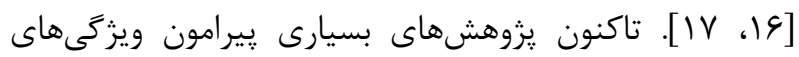
ساختارى، ريخت شناسى، إيتيكى، الكتريكى، مغناطيسى و ونيرى

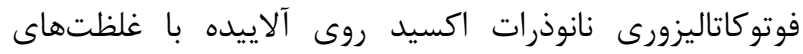
مختلف مس تهيه شده با روشهاى متفاوت انجام شده است

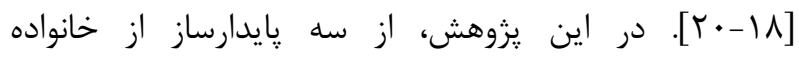

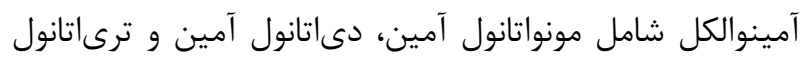

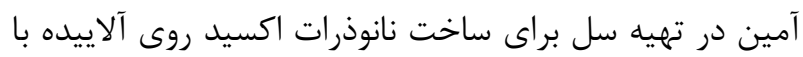

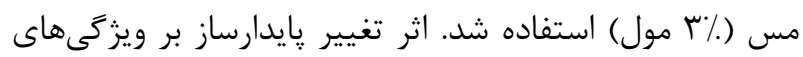

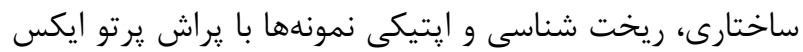
(XRD)

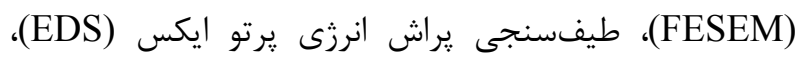<smiles>CC(O)CN(C(C)O)C(C)CO</smiles>

TEA

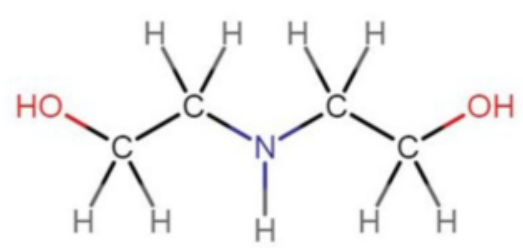

DEA

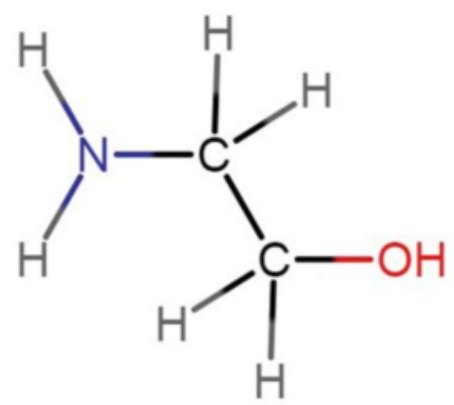

MEA 
را نشان مى دهد. جنان كه ديده مىشود، الكوى همه

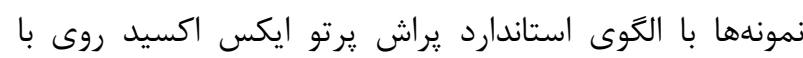
ساختار شش شوش ورتسايت (JCPDS No. 79-0206) همخوانى دارند. نمونه تهيه شده با TEA داراى جهت

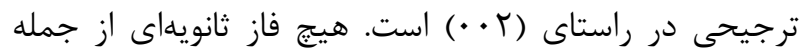

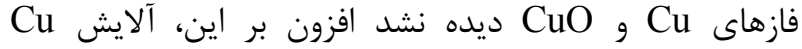

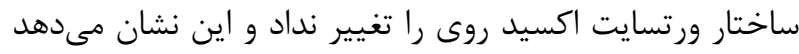
كه

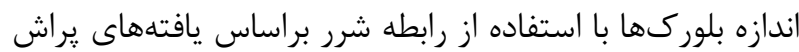

$$
D=\frac{K A}{\beta \cos \theta}
$$$$
\text { يرتو X محاسبه شد (جدول بل (1): }
$$

اندازه ميانكين بلورك، م يهناى قله يراش در نيم ارتفاع

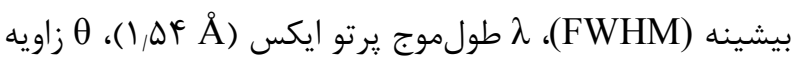
برات مربوط به قله يراش و K ضريب ثابتى است كه به شكل بلوركها، توزيع آنها و طولموج بستخى دارد و در اين يزوهش برات

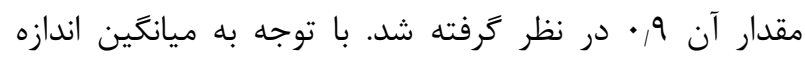
بلورى محاسبهشده براى هر سه نمونه (جدول ())، بهترين كيفيت بلورى را نمونه تهيهشده با دىاتانول آمين داراست.
مشخصه يابى

براى تعيين ساختار بلورى نانوذرات، يراش يرتو ايكس (XRD)

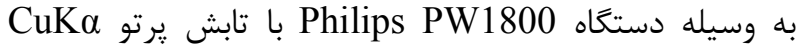

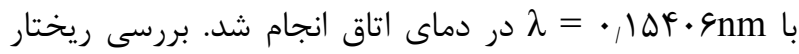

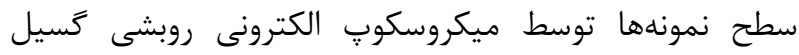
ميدانى (FESEM) با دستخاه Mira3TSCAN XMU انجام كرديد. عنصر سنجى توسط طيفسنج يراش انرزى يرتو ايكس

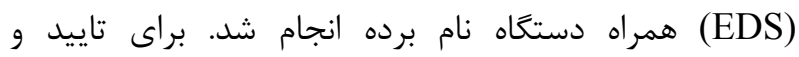
تشخيص عاملهاى شيميايى از طيفسنجى تبديل فوريه فروسرخ (FTIR) با دستغاه Alpha-Bruker استفاده شد. براى تعيين كاف نوارى ايتيكى نانوذرات از طيفسنج بازتاب

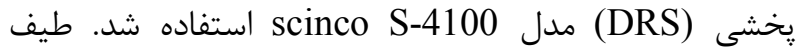
نورتابى نمونهها توسط دستخاه Perkin Elmer Ls-55 بررسى لنى كرديد.

نتايج و بحث شكل r الكَوى تراش برتو ايكس نانو ذرات اكسيد روى آلاييده

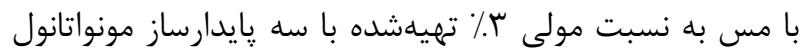

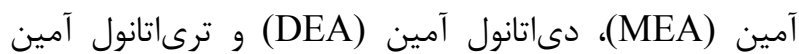

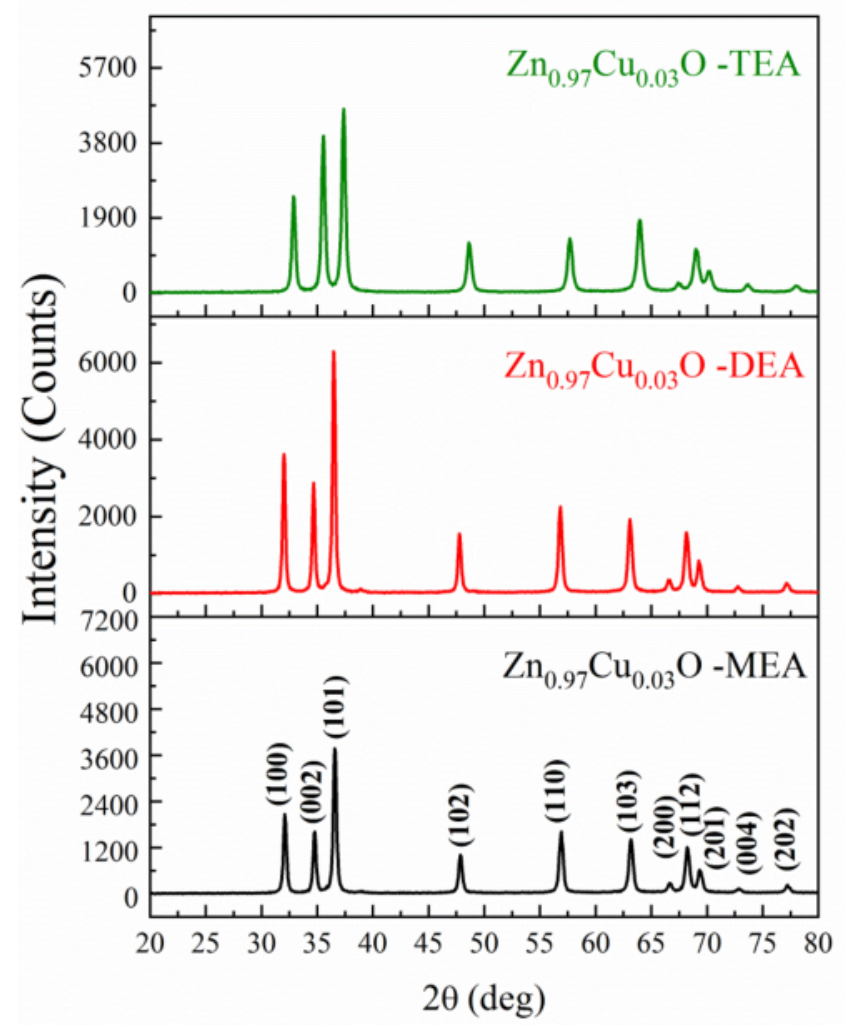

شكل الگوى يراش يرتو ايكس نانو ذرات 
جدول إِارامترهاى ساختارى نانوذرات

\begin{tabular}{|c|c|c|c|c|c|c|c|}
\hline $\mathrm{c}(\AA)$ & $\mathrm{a}(\AA)$ & (kJm" & تنش (Mpa) & كرنش همسانكرد (3010 × & |اندازه بلور ك (nm) & |اندازه بلورك (nm) & \\
\hline$\Delta, \Delta, q$ & r,TIV & $\cdot .4 q$ & $114 \cdot 1$ & $\cdot \wedge \vee V$ & $\mu \cdot \wedge$ & $r$ r, & MEA \\
\hline$\Delta, \Delta \wedge r$ & T,TtQ & .1 .94 & $|\Delta V| T$, & $1, \pi 1$ & $F \cdot 1 V$ & $r \Delta, \Lambda$ & DEA \\
\hline$\Delta, \Delta \wedge \Lambda$ & TTKA & - TUS & $r \Delta V, q r$ & 1,91 & $r G, F V$ & $r \cdot r^{\prime}$ & TEA \\
\hline
\end{tabular}

فيزيكى آنها اثر بحذارد. در مدل كرنش همسانكرد (ISM)

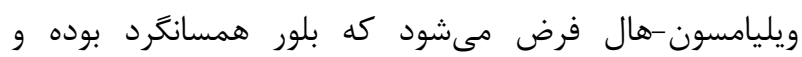

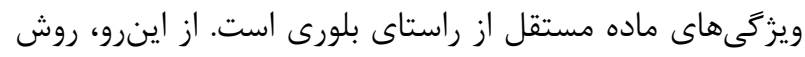

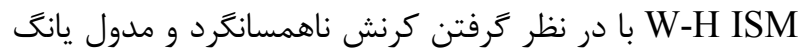
(Yhkl)

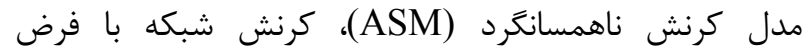

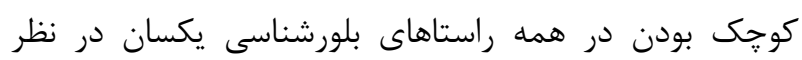

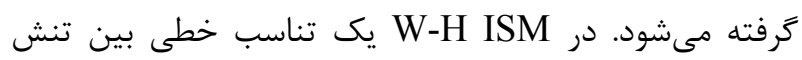

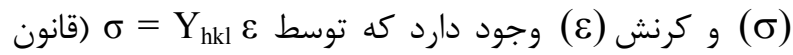

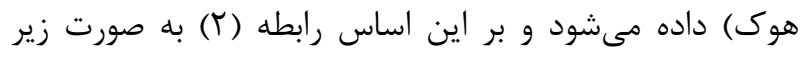

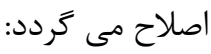
$\beta_{h k l} \cos \theta_{h k l}=\frac{K \lambda}{D_{v}}+\frac{4 \sigma \sin \theta_{h k l}}{Y_{h k l}}$
اندازه بلوركها با در نظر كرفتن اثر كرنش و استفاده از رابطه ويليامسون- هال (W-H) نيز محاسبهشد:

$$
\beta \cos \theta=\frac{R A}{D}+4 \varepsilon \sin \theta
$$

در اين رابطه، ع كرنش، و ساير يارامترها مانند توضيح بالا هستند. با توجه به خطى بودن اين رابطه، نمودار

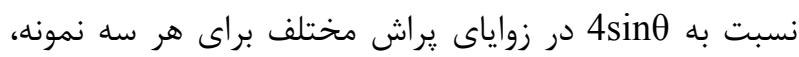

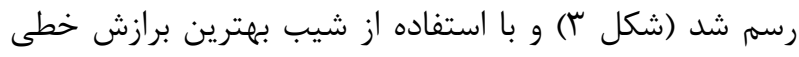

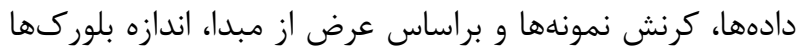

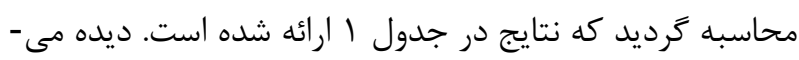

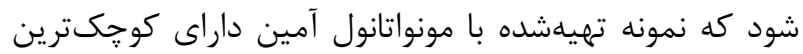

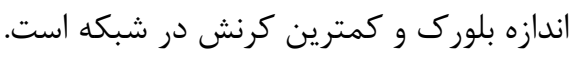

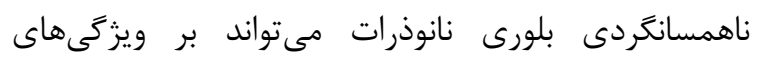

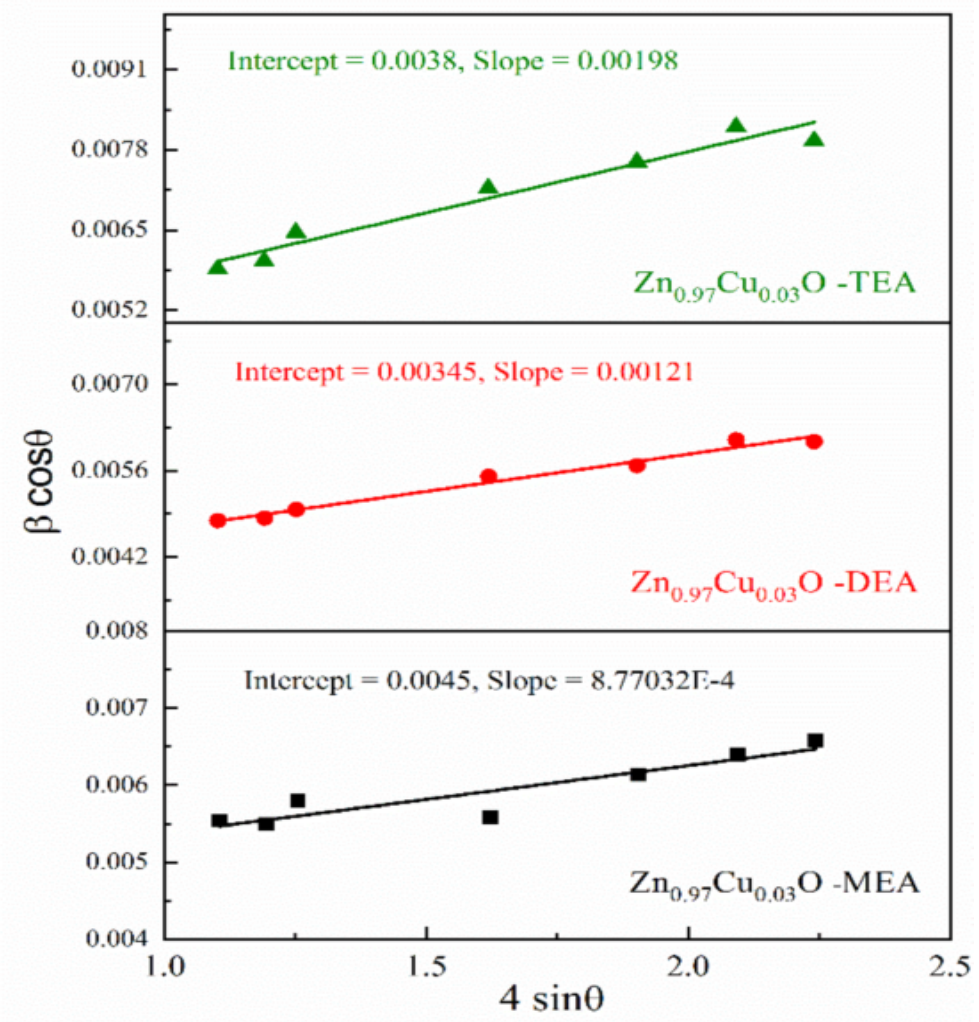

شكل r نمودار كرنش همسانكَرد ويليامسون- هال نانوذرات Zn 
توجه به رابطه جكالى انرزى و كرنش به شكل زير بازنويسى

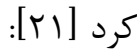
$\beta_{h k l} \cos \theta_{h k l}=\frac{k \lambda}{D_{v}}+4 \sin \theta_{h k l}\left(\frac{2 u}{Y_{h k l}}\right)^{1 / 2}$

جعالى انرزى و اندازه بلورك به ترتيب از شيب و عرض از مبدا نمودار دست آمدند و در جدول إرائه شدهاند. براى ساختار ششكوش، ثابتهاى شبكه (c,a) از رابطه زير به $\frac{1}{d h k l}=\frac{4\left(h^{2}+h k+k^{2}\right)}{3 a^{2}}+\frac{l^{2}}{e^{2}}$

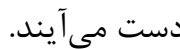
شاخصهاى ميلر دسته صفحات و d فاصله ميان آنها،

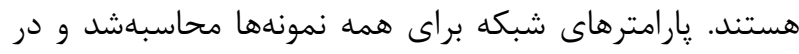

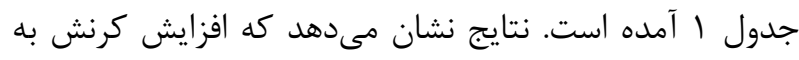
افزايش پارامترهاى شبكه a و c كمك كرده و منجر به جهتكيرى قوى صفحه (r +•) در CZO-TEA نسبت به دو نمونه

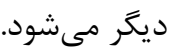

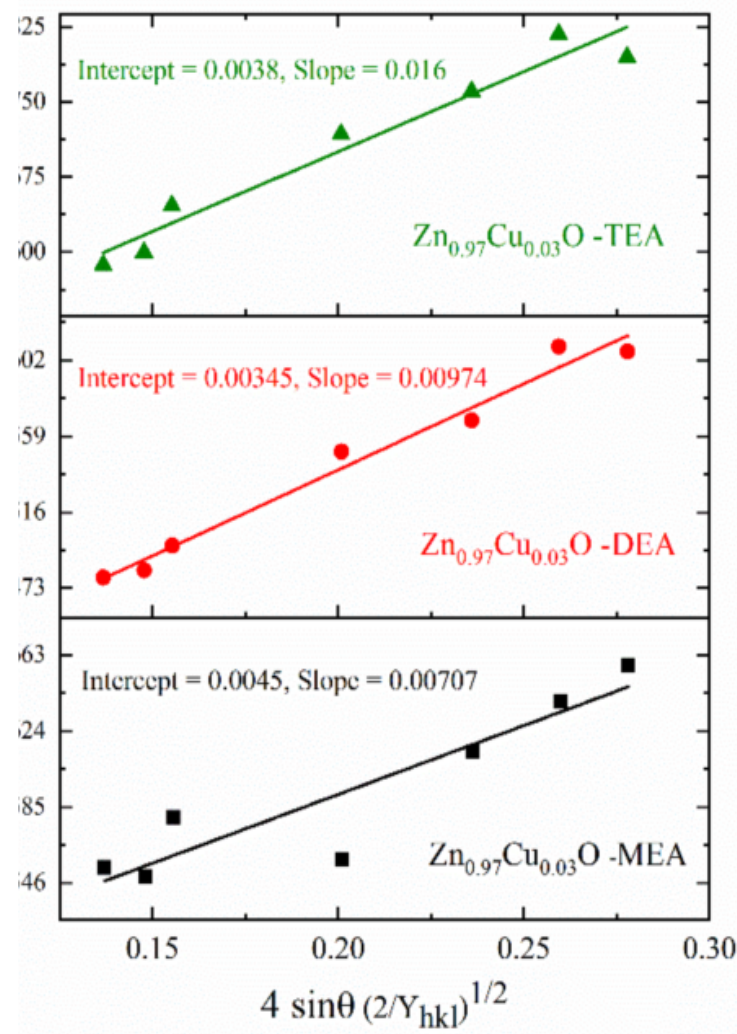

براى ساختار ششكوشى، معكوس مدول يانگ در راستاى دلخواه [hkl] رامىتوان با رابطه زير بيان كرد [إr]:

$$
Y_{h k l}=\frac{\left[h^{2}+\frac{(h+2 k)^{2}}{3}+\left(\frac{a l}{c}\right)^{2}\right]^{2}}{s_{11}\left(h^{2}+\frac{(h+2 k)^{2}}{3}\right)^{2}+s_{33}\left(\frac{a l}{c}\right)^{4}+\left(2 s_{13}+s_{44}\right)\left(h^{2}+\frac{(h+2 k)^{2}}{3}\right)\left(\frac{a l}{c}\right)^{2}}
$$

مقادير كرنش ناهمسانكرد W-H ASM با مقادير يُيشين كرنش همسانكرد (

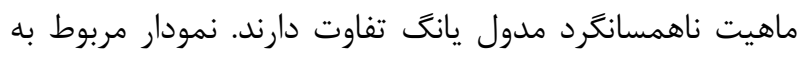
مدل كرنش ناهمسانكرد در شكل بٔ الف نشان داده شده است.

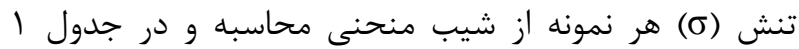
كزارش شده است. براى تعيين جكالى انرزى تغيير شكل بلور مىتوان از مدل

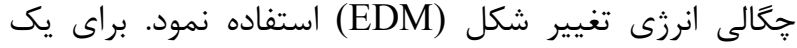

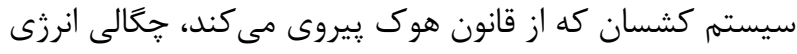

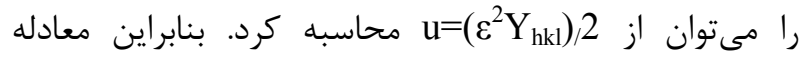

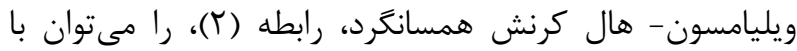

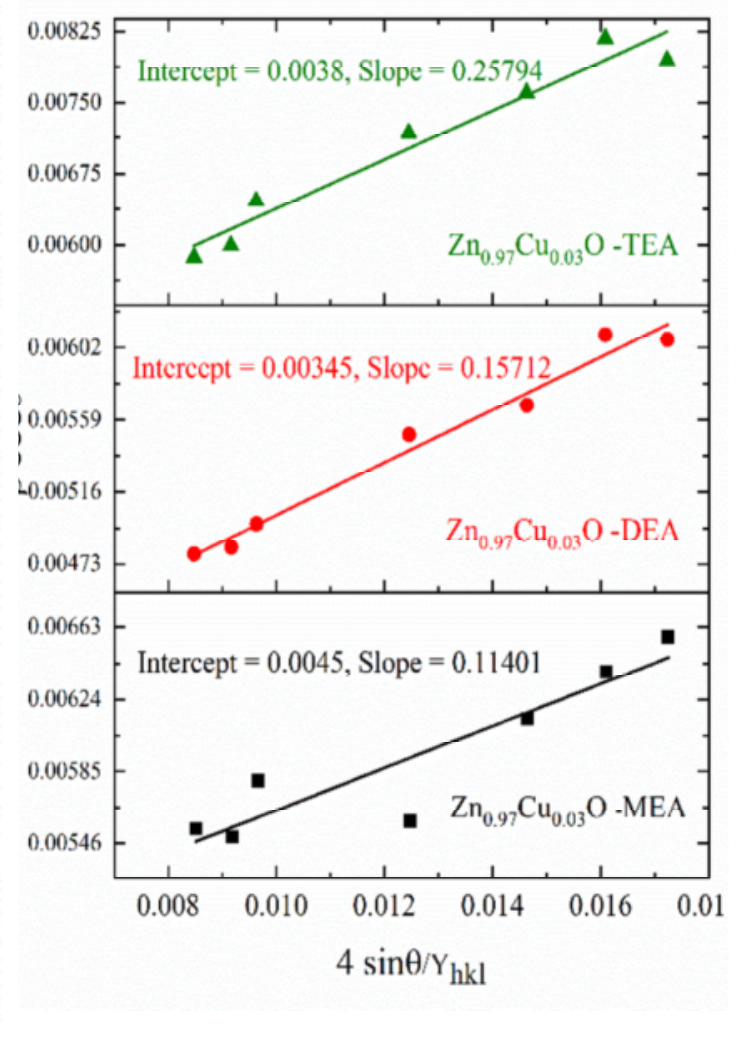

شكل F نمودارهاى مدل (الف)كرنش ناهمسانكرد و (ب) جحالى انرزى تغيير شكل همسانكرد ويليامسون- هال نانوذرات Zn0.97Cu0.03O تهيه شده با يايدارسازهاى مختلف. 


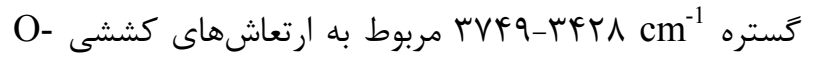

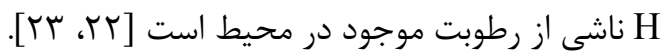

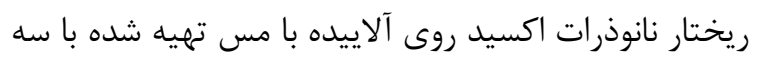
پايدارساز متفاوت، توسط ميكروسكوٍ الكترونى روبشى كسيل

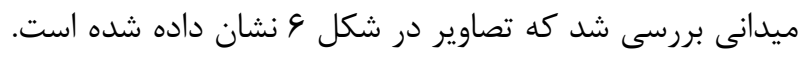
تصاوير نشانكر ذرات اندازه كروى با گستره نانومتر هستند داندان

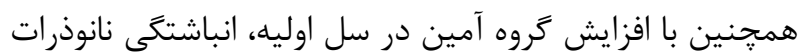
كاهش يافته و سطح موثر افزايش مى يابد.

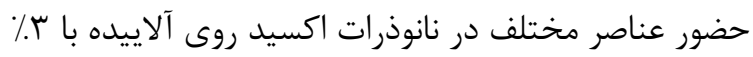

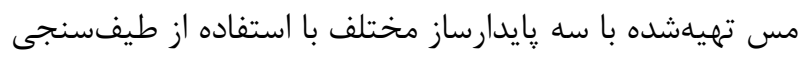

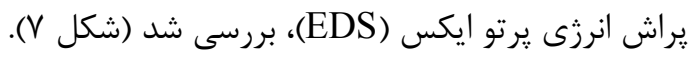

در شكل ه، طيف FTIR نانوذرات شده است. شدت و جايكاه قلهها در نمونهها با تغيير بايدارسازها

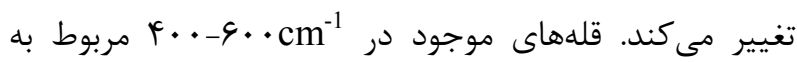

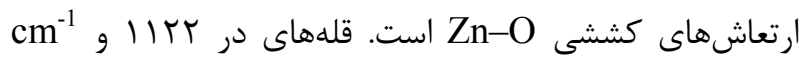

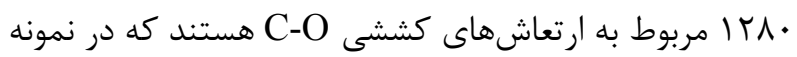
دى اتانول آمين شدت آنها بسيار كمتر است. قله هاى در ه

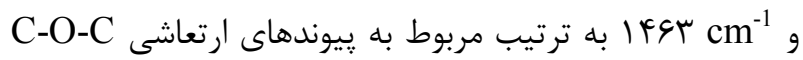
- هستند. قله موجود در C=O هاى خمشى H-O-H آب موجود در نانوبلور ZnO است. قله

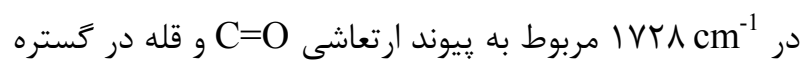
ن-H

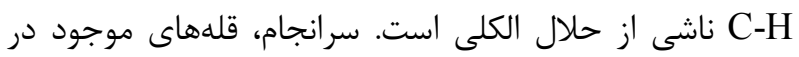

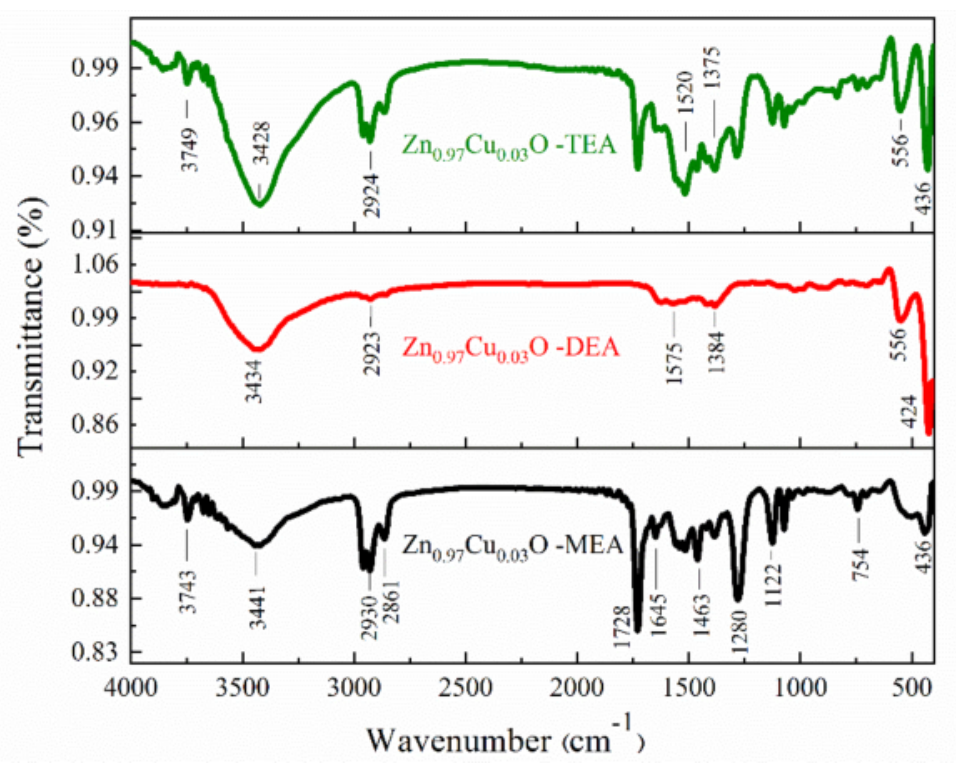

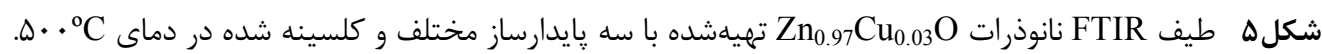
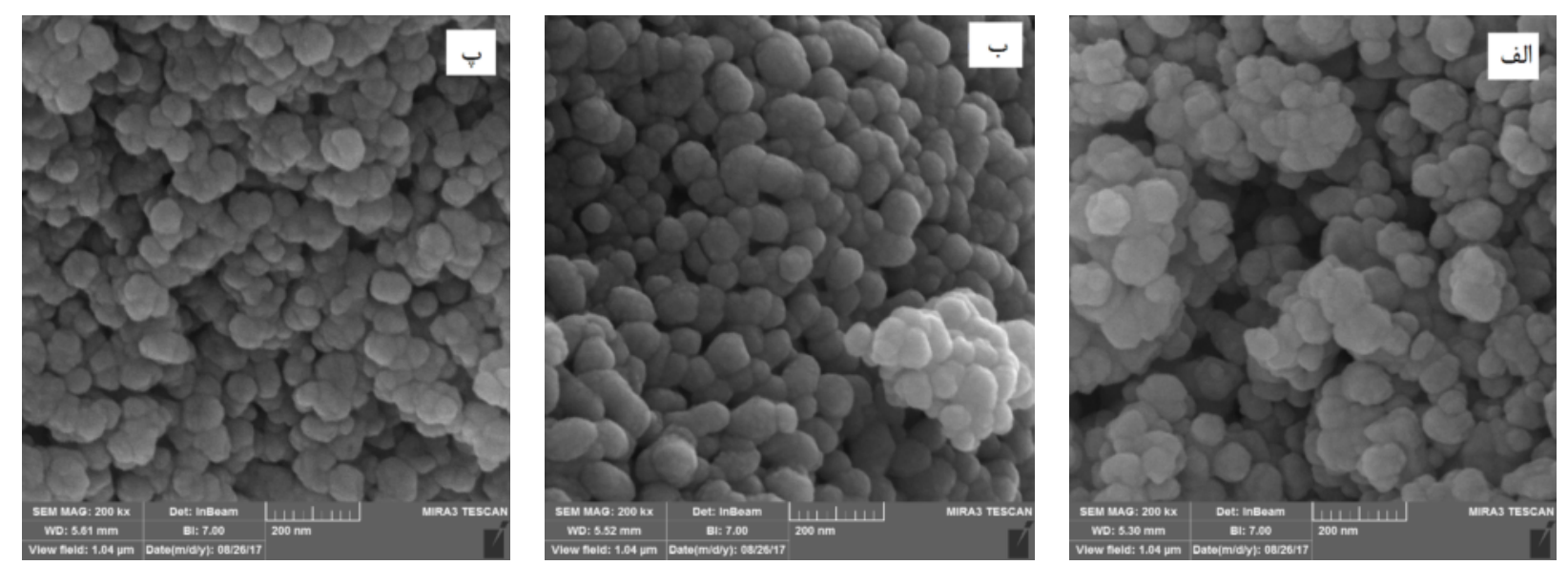

شكل \& تصاوير FESEM نانوذرات Z r... kx 

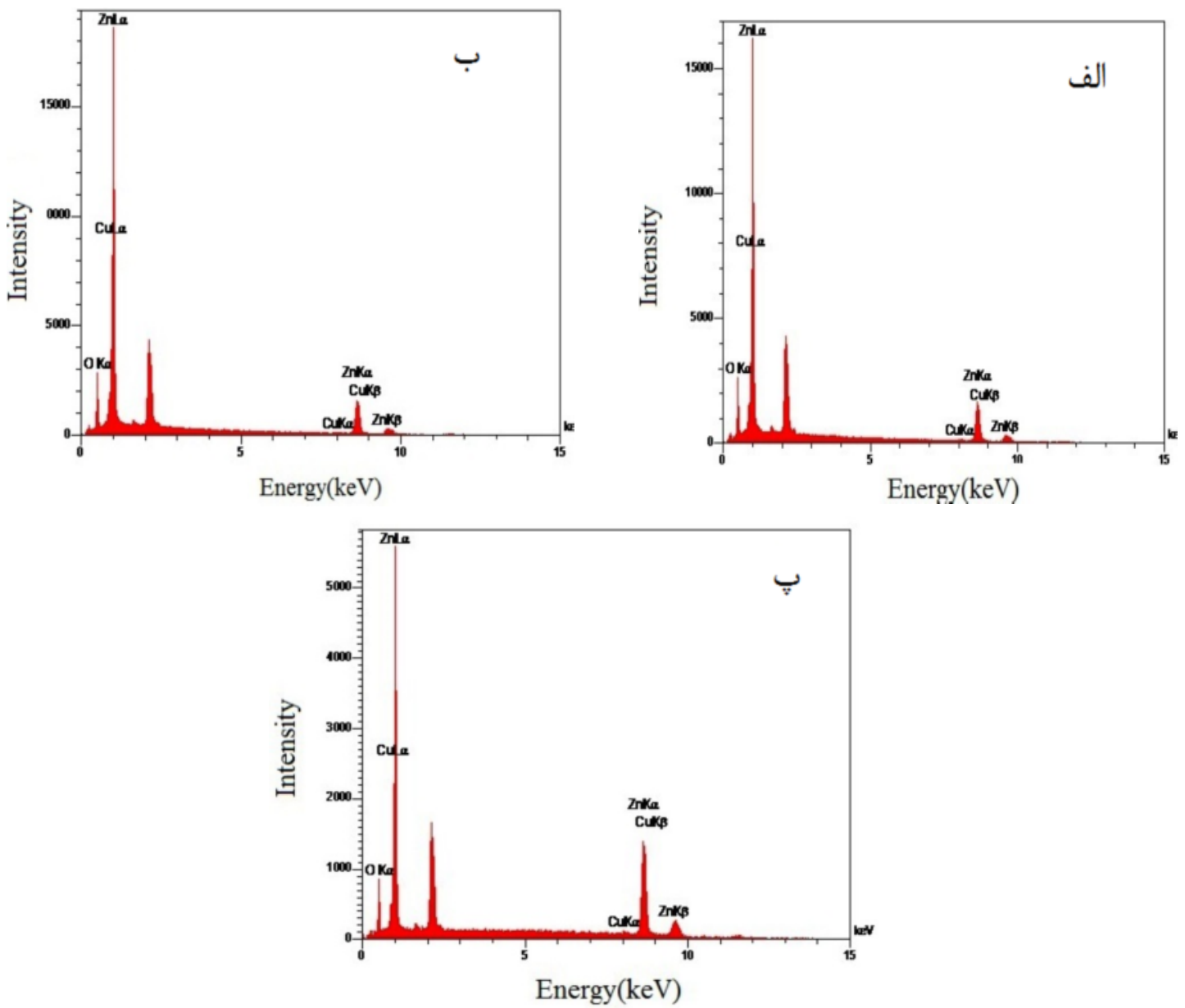

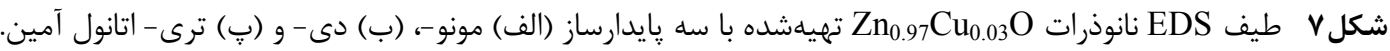

جذب قوى و A مقدارى ثابت است. توان n به نوع كذار بستخى

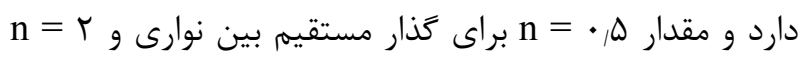
براى گذار غيرمستقيم است [Y؟] با توجه به كذار مستقيم در اكسيد روى، با رسم نمودار نسبت به hv ((F(R)/d)*hv) منحنى (شكل ^ 1 ب) مقدار گاف نوارى هر سه نمونه تعيين شد.

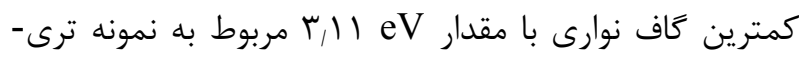
اتانول آمين و بيشترين مقدار

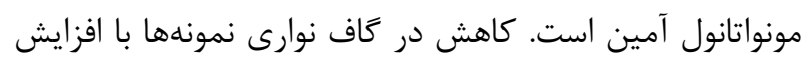

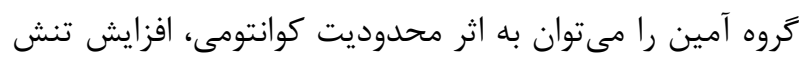

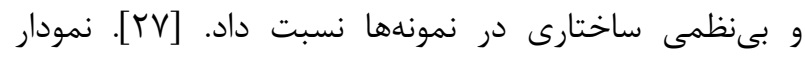
ارتباط بين نوع يايدارساز مورد استفاده در تهيه سل دور و

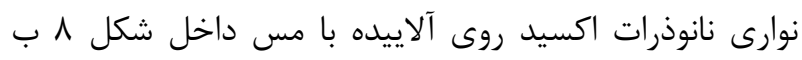
نشان داده شده است.

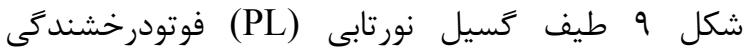
نانوذرات اكسيد روى آلاييده با مس تهيه شده با پايدارسازهاى نورئي

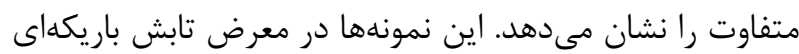

طيف بازتاب يخشى نانو ذرات اكسيد روى آلاييده با سـ٪ مس

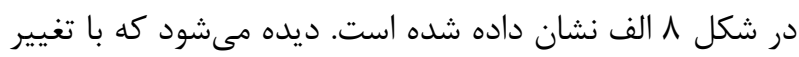
يايدارساز ميزان بازتاب يخشى تغيير مى كند و جابجايى در لبه

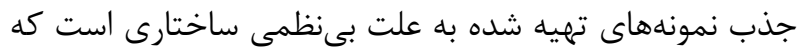

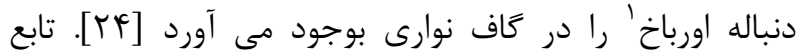

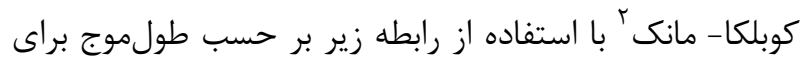
$F(R)=\frac{(1-R)^{2}}{2 R}$

همه نمونهها محاسبه شد [YU] كه R طيف بازتاب نمونههاست. كاف نوارى با استفاده از رابطه تاوك `محاسبه كرديد.

$$
\alpha h v=A\left(h v-E_{g}\right)^{n}
$$

در اين رابطه، hv انرزى فوتون، $\alpha$ ضريب جذب و معادل با d ضخامت قرص تهيه شده از نمونه است) در ناحيه d $F(R) d$

1- Urbach Tail

2- Kubelka-Munk

3- Tauc 


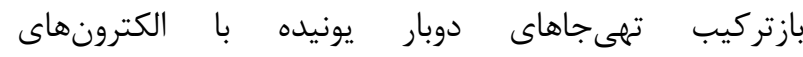

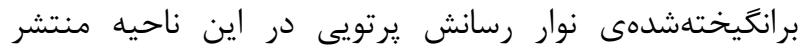

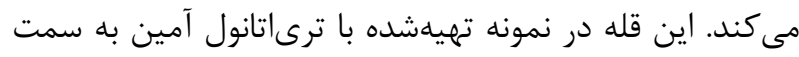

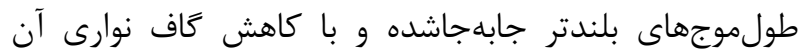

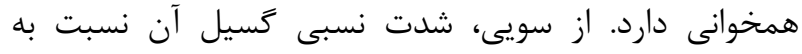

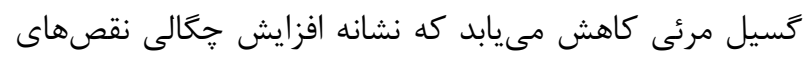

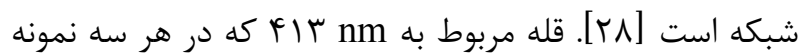

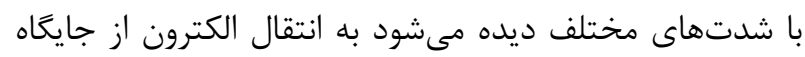

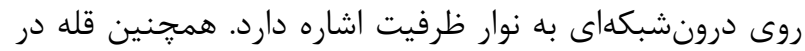

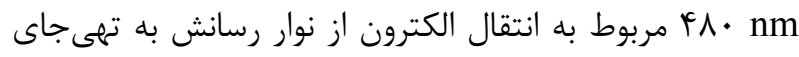

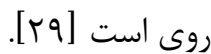

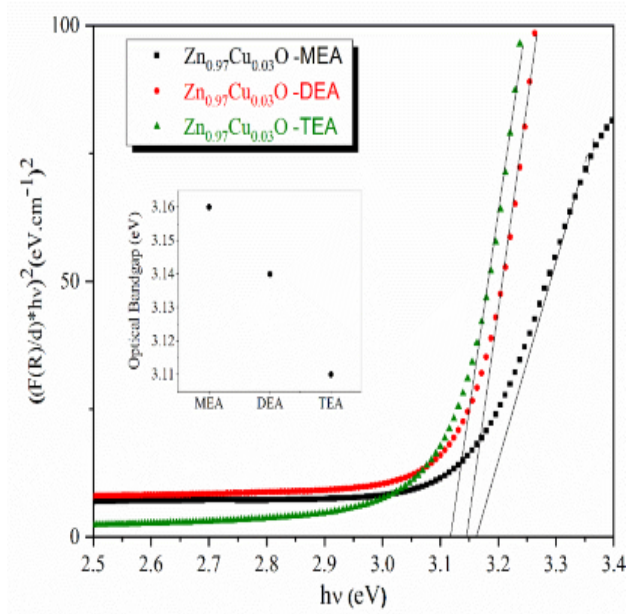

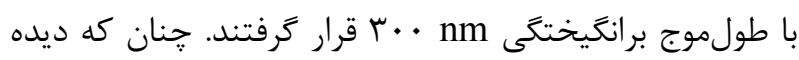

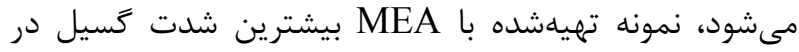

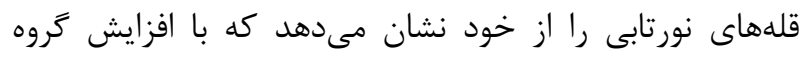

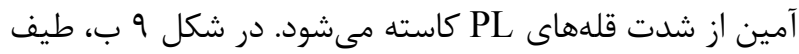

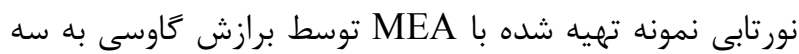

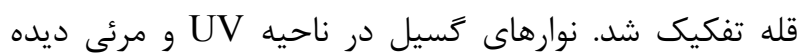

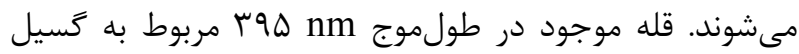

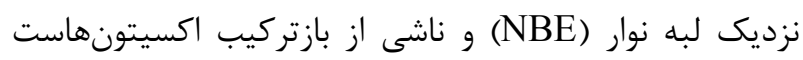

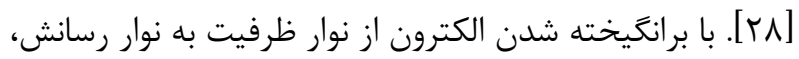

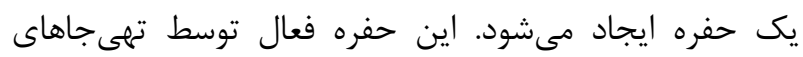

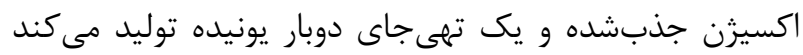

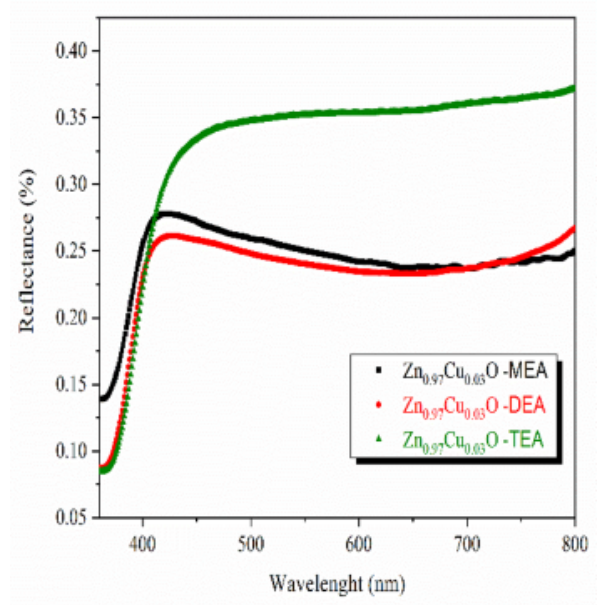

شكلى (الف) طيف بازتاب پخشى و (ب) نمودار تعيين كاف نوارى نانوذرات Zn آمين. (- آن
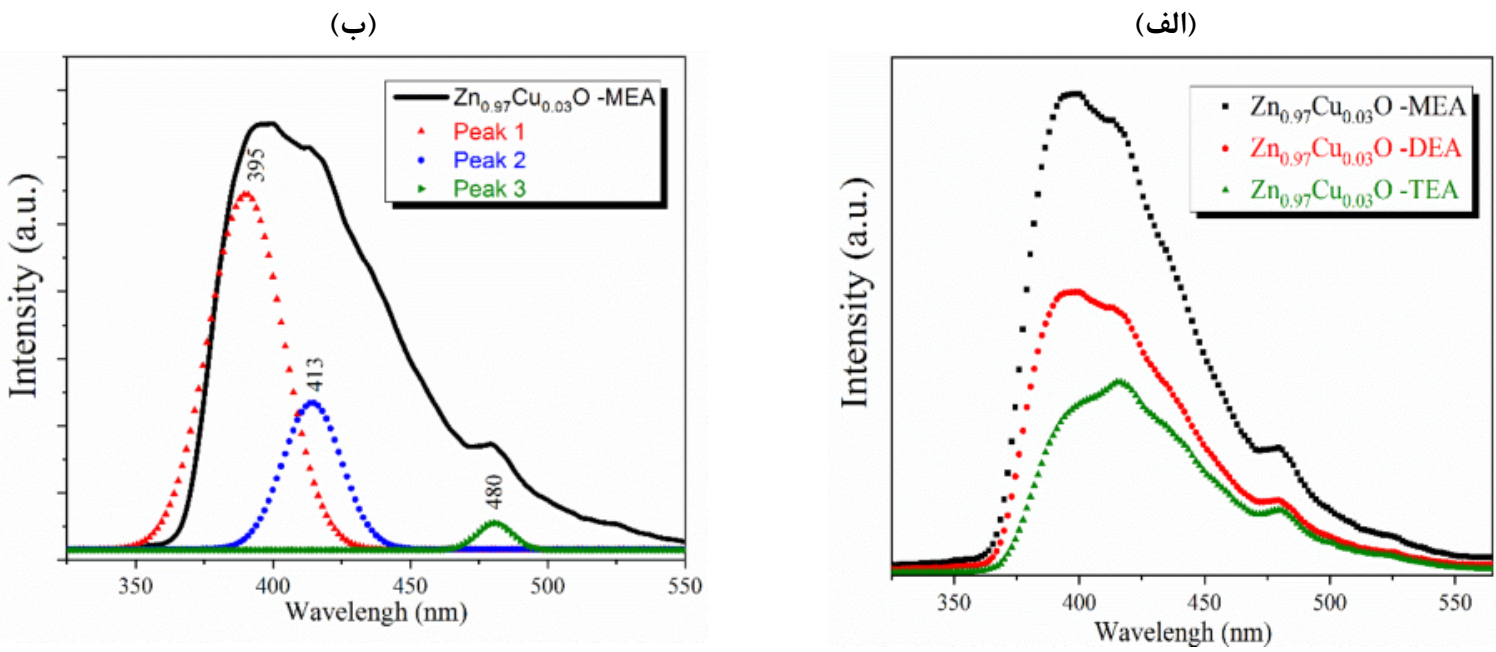

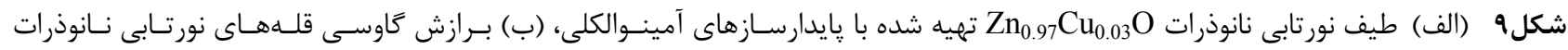

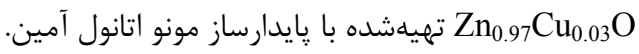


oxide nanorods for polymer solar cells application", Iranian Journal of Crystallography and Mineralogy 25 (4) (2018) 885-894.

[4] Yuonesi M., Izadifard M., Ghazi M. E., Esmaili Ghodsi F., Influence of $\mathrm{Co}$ and Fe substitution on optical and structural properties of zinc oxide thin films Iranian Journal of Crystallography and Mineralogy 19 (3) (2011) 65-72.

[5] Zargar Shoushtari M., Poormoghadam A., Farbod M., Fabrication and study of structural, optical and magnetic properties of $\mathrm{Zn}_{1-x} \mathrm{Ni}_{x} \mathrm{O}$ nanoparticles", Iranian Journal of Crystallography and Mineralogy 24 (2) (2016) 309-316.

[6] Sarraf N., Hasanpour A., Hashemizade Aghda A., Akhound A., Investigation of room temperature ferromagnetic behavior in Mn doped $\mathrm{ZnO}$ nanoparticles", Iranian Journal of Crystallography and Mineralogy 23 (2) (2015) 383-388.

[7] Nimbalkar A.R., Patil M.G., Synthesis of highly selective and sensitive $\mathrm{Cu}$-doped $\mathrm{ZnO}$ thin film sensor for detection of $\mathrm{H}_{2} \mathrm{~S}$ gas", Materials Science in Semiconductor Processing 71 (2017) 332-341.

[8] Yang S., Zhang Y., Mo D., Spectroscopic ellipsometry studies of sol-gel-derived Cu-doped ZnO thin films", Thin Solid Films 571 (2014) 605608.

[9] Joshi K., Rawat M., Gautam S.K., Singh R.G., Ramola R.C., Singh F., Band gap widening and narrowing in Cu-doped $\mathrm{ZnO}$ thin films", Journal of Alloys and Compounds 680 (2016) 252-258.

[10] Lupan O., Pauporte T., Viana B., Aschehoug P., Electrodeposition of $\mathrm{Cu}$-doped $\mathrm{ZnO}$ nanowire arrays and heterojunction formation with $p$-GaN color tunable light emitting diode applications", Electrochimica Acta 56 (2011) 10543-10549.

[11] Fang M., Tang C.M., Liu Z.W., Microwaveassisted hydrothermal synthesis of Cu-doped $\mathrm{ZnO}$ single crystal nanoparticles with modified photoluminescence and confirmed ferromagnetism", Journal of Electronic Materials 47 (2018) 1390-1396.

[12] Giraldi T.R., Santos G.V.F., Mendonca V.R., Ribeiro C., Weber I.T., Effect of synthesis parameters on the structural characteristics and

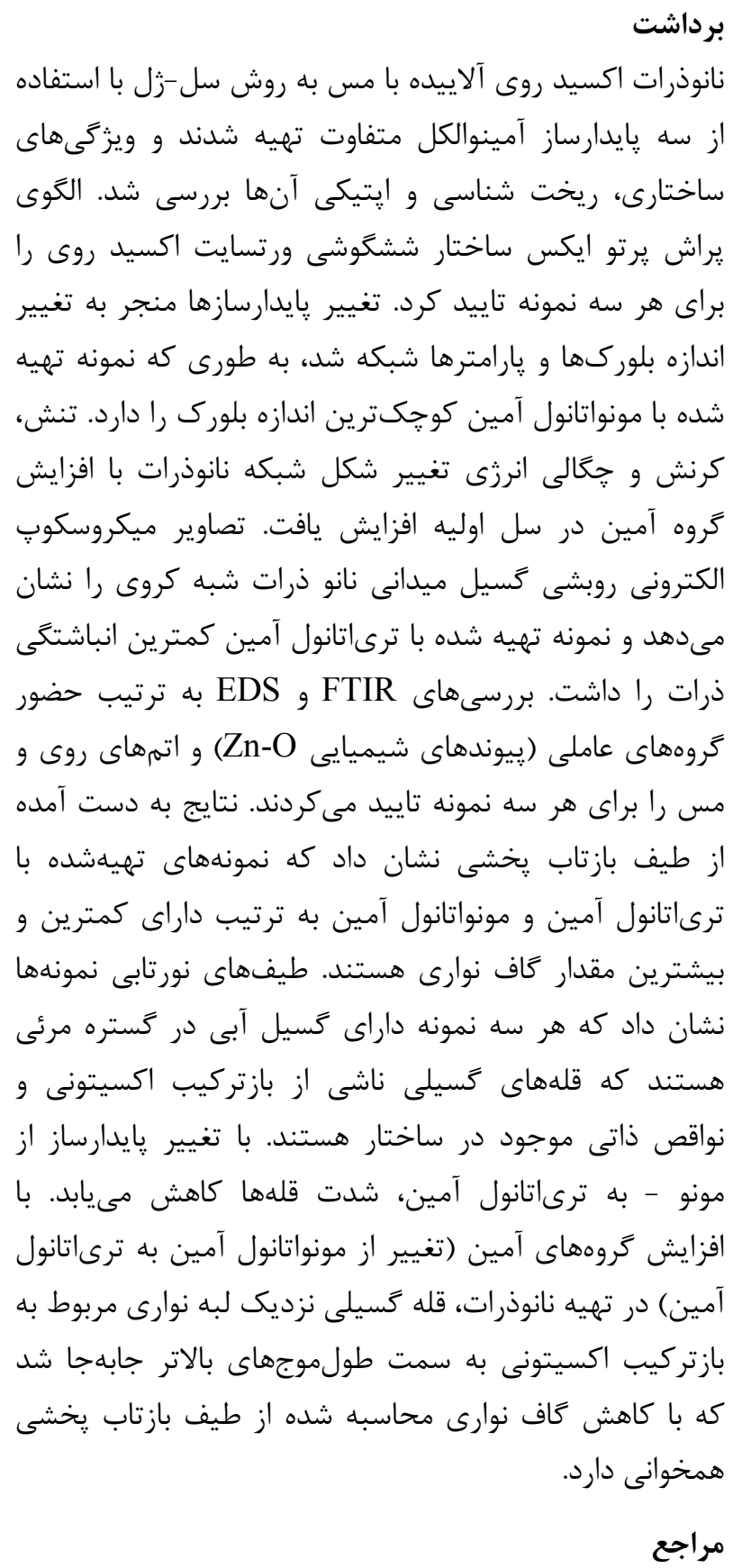

[1] Jagadish C., Pearton SJ., "Zinc Oxide Bulk, Thin Films and Nanostructures: Processing, Properties, and Applications ",Elsevier New York, 2006.

[2] Deshwal M., Arora A., Enhanced acetone detection using Au doped $\mathrm{ZnO}$ thin film sensor", Journal of Materials Science: Materials in electronics 29 (2018) 15315-15320.

[3] Naderi M., Zargarshoshtari M., Kazeminejad I., Investigation of precursor solution concentration effect on morphology and optical properties of zinc 
[21] Khorsand Zak A., Abd. Majid W.H.,Abrishami M.E., Yousefi R., X-ray analysis of $\mathrm{ZnO}$ nanoparticles by WilliamsoneHall and sizeestrain plot methods", Solid State Science 13 (2011) 251-256.

[22] Vajargah P.H., Abdizadeha H., Ebrahimifarda R., Golobostanfard M.R., Sol-gel derived $\mathrm{ZnO}$ thin films: Effect of amino-additives", Applied Surface Science 285 (2013) 732- 743.

[23] Forouzani M., Mardani H.R., Ziari M., Malekzadeh A., Biparva P., 'Comparative study of oxidation of benzyl alcohol: Influence of Cu-doped metal cation on nano $\mathrm{ZnO}$ catalytic activity", Chemical Engineering Journal 275 (2015) 220226.

[24] Burstein E., "Anomalous optical absorption limit in InSb", Physical Review Journals Archive 93 (1954) 632-633.

[25] Choudhury B., Choudhury A., Tailoring luminescence properties of $\mathrm{TiO}_{2}$ nanoparticles by Mn doping," Journal of Luminescence 136 (2013) 339-346.

[26] Tauc J., Amorphous and Liquid Semiconductors, Plenum Press, New York, 1974. [27] Prasada Rao T., Santhosh Kumar M.C., Anbumozhi Angayarkanni S., Ashok M., Effect of stress on optical band gap of $\mathrm{ZnO}$ thin films with substrate temperature by spray pyrolysis ", Journal of Alloys and Compounds 485 (2009) 413-417.

[28] Monemdjou A., Ghodsi F.E., Mazloom J., The effects of surface morphology on optical and electrical properties of nanostructured AZO thin films: fractal and phase imaging analysis", Superlattices Microstruct. 74 (2014) 19-33.

[29] Oliva J., Torres L.D., Castro A.T., Salas P., Mayen L.P., Rosa E.D.L, Effect of TEA on the blue emission of $\mathrm{ZnO}$ quantum dots with high quantum yield", Optical Materials Express 5 (2015) 1109-1121. photocatalyticactivity of $\mathrm{ZnO}$,' Materials Chemistry and Physics 136 (2012) 505-511.

[13] Kumar K.D.A, Ganesh V., Shkir M., AlFaify S., Valanarasu S., Effect of different solvents on the key structural, optical and electronic properties of sol-gel dip coated AZO nanostructured thin films for optoelectronic applications", Journal of Materials Science: Materials in electronics 29 (2018) 887-897.

[14] Winer I., Shter G.E., Lahav M.M, Grader G.S., Effect of solvents and stabilizers on sol-gel deposition of Ga-doped zinc oxide TCO films", Journal of Materials Research 26 (2011) 13091315.

[15] Bekkari R., Laanab L., Boyer D., Mahiou R., Jaber B., Influence of the sol gel synthesis parameters on the photoluminescence properties of $\mathrm{ZnO}$ nanoparticles", Materials Science in Semiconductor Processing 71 (2017) 181-187. [16] Sakka S., Handbook of Sol-Gel Science and Technology Processing Characterization and Applications1st Edition, Springer.

[17] Thongsuriwong K., Amornpitoksuk P., Suwanboon S., The effect of aminoalcohols (MEA, DEA and TEA) on morphological control of nanocrystalline $\mathrm{ZnO}$ powders and its optical properties", Journal of Physics and Chemistry of Solids 71 (2010) 730-734.

[18] Elilarassi R., Sambasiva Rao P., Chandrasekaran G.,"Diluted magnetic semiconductor properties in $\mathrm{Zn}_{1-x} \mathrm{Cu} x \mathrm{O}$ nanoparticles synthesized by sol gel route", Journal of Sol-Gel Science and Technology, 57 (2011) 101-108.

[19] Koao L.F., Dejene B.F., Swart H.C., "The effect of $\mathrm{Cu}^{2+}$ on structure, morphology and optical properties of flower-like $\mathrm{ZnO}$ synthesized using the chemicalbath deposition method", Journal of Physica B 439 (2014) 173-176.

[20] Labhane P. K., Huse V. R., Patle L. B., Chaudhari A. L., Sonawane G. H., "Synthesis of Cu Doped ZnO Nanoparticles: Crystallographic, Optical, FTIR, Morphological and Photocatalytic Study", Journal of Materials Science and Chemical Engineering 3 (2015) 39-51. 